\title{
Effect of Antiretroviral Therapy With Tenofovir, Lamivudine And Dolutegravir On Respiratory And Peripheral Muscles Strengh In People Living With Hiv/Aids
}

Renata de Oliveira Cardoso ( $\sim$ tia_tata@hotmail.com )

Universidade Federal de Pernambuco https://orcid.org/0000-0001-7274-0372

Paulo Sérgio Ramos de Araújo

Centro de Pesquisas Aggeu Magalhaes

Juliana Barros Maranhão

Hospital de Cancer de Pernambuco

Marco Aurélio de Valois Correia Júnior

Universidade de Pernambuco - Campus de Nazare da Mata

Eduarda Lubambo Costa

Universidade Federal de Pernambuco

Research article

Keywords: Dolutegravir, Respiratory muscle weakness, Handgrip strength, HIV / AIDS

Posted Date: October 4th, 2019

DOI: https://doi.org/10.21203/rs.2.15545/v1

License: (c) (i) This work is licensed under a Creative Commons Attribution 4.0 International License.

Read Full License 


\section{Abstract}

Background Some antiretrovirals (ARVs) cause muscle toxicity and their use has been attributed to beginning of respiratory and peripheral muscle weakness in people living with HIV/AIDS (PLWHA) on treatment. Dolutegravir (DTG) has been adopted by Brazil as a first-line regimen with Tenofovir/Lamivudine (TDF/3TC) since 2017, with low toxicity profile. Due to the short use of this regimen, we have not found data in the literature regarding its effects in the respiratory and peripheral muscles in PLWHA. The aim of this study was to compare respiratory and peripheral muscle strength before and after start of this new combined ART (TDF/3TC/DTG).

Methods Descriptive, longitudinal and prospective study, observational and analytical with 41 PLWHA evaluated before the initiation of antiretroviral therapy (ART) (T0) which of these, 28 were reevaluated after more than 50 days of treatment (T1).The assessments of maximum functional capacity (six-minute walk test distance), maximal inspiratory (MIP) and expiratory (MEP) pressures and handgrip strength (HGS) were performed using standardized methods. In addition, laboratory data (CD4, CD4/CD8 ratio and viral load-VL) were collected. Shapiro-Wilk test was applied for normality while Fisher's exact test and ttest or Wilcoxon test were used for comparisons of categorical and continuous variables, respectively. Pearson or Spearman correlations were used according to data normality and p-value $<0.05$ were considered significant for all analyzes.

Results The frequency of peripheral muscle weakness in patients evaluated at T0 was $97.6 \%$, while $31.7 \%$ had inspiratory and / or expiratory muscle weakness. HGS was positively correlated with CD4 $(p=0.027)$ and negatively correlated with VL $(p=0.046)$. Both MIP $(p=0.0176)$ and HGS $(p=0.0018)$ showed improvement in T1.

Conclusion ART combined with TDF / 3TC / DTG increased MIP and HGS after more than 50 days of treatment. Cohort studies are needed to better understand the action of these medications on PLWHA musculature under treatment.

\section{Introduction}

According to reported data by the United Nations group Program on Human Immunodeficiency Virus / Acquired Immunodeficiency Syndrome (HIV / AIDS) until 2018 there were 37.9 million people living with HIV/AIDS (PLWHA) in the world, 23.3 million with access to antiretroviral therapy (ART) (1) and, after almost four decades of the AIDS pandemic, HIV infection remains a major public health problem (2). Over the years, the scientific community has been trying to understand the effect of HIV on the infected organism, and studies have shown that PLWHA have a chronic inflammatory status caused by the virus, and this is associated with factors such as immune activation, secondary to several causes (3). This persistent immune activation increases the rate of mitochondrial apoptosis induced by pro- 
inflammatory cytokines and HIV itself, impairing mitochondrial deoxyribonucleic acid (mtDNA) in untreated HIV-infected individuals. On the other hand, the association of cytotoxic effects of some antiretrovirals (ARVs) with this reduction in mtDNA could contribute to mitochondrial toxicity in patients on ART. Therefore, HIV infection alone seems to affect mitochondria, contributing to the mitotoxicity observed in individuals in use of ART (4).

ART has changed the natural course of the disease, turning it into a chronic condition, and immediate initiation of treatment has been recommended for all PLWHA, independently of their clinical and / or immune stage (5) aiming not only improving the quality of life of these individuals, but also reducing the risk of virus transmission. (6). The adherence to treatment controls viral replication, decreases immune activation and takes to preservation and / or restoration of the immune system in most patients $(7,8)$, avoiding, then, complications of the HIV / AIDS complex, which include fatigue, disability, emergence of opportunistic infections (OIs) and muscle loss (9).

Although ARVs have short-term adverse effects, the most characteristic ones appear in the long term and are related to their mitotoxicity (8). Studies have suggested a correlation between ART and the incidence of skeletal mitotoxicity (10), peripheral muscle weakness (dynapenia) (11), inspiratory muscle weakness (IMW) (12) and expiratory muscle weakness (EMW) (13). The decline in handgrip strength (HGS) may contribute to decreased life expectancy and worse quality of life with aging (14). On the other hand, the IMW limits the volume of inhaled air before coughing, indirectly decreasing the maximal expiratory pressure (MEP), which is intrinsically linked to the ability of the respiratory muscles to maintain an effective cough. Thus, respiratory muscle weakness (RMW) is correlated with the onset of respiratory infections, as impaired cough is not able to promote removal of airway secretions $(13,15)$.

Advances have been made in combating HIV infection in recent years, especially with improved ART $(16,17)$ although it is believed that these new ARV drugs induces fewer metabolic disorders than older drugs such as mitotoxicity, their long-term effects are not yet completely understood $(18,19)$. In this context emerged Dolutegravir (DTG), adopted by Brazil in January 2017, replacing Efavirenz (EFV), which was part of the old first-line scheme together with Tenofovir (TDF) and Lamivudine (3TC) (20). This new medication has a low profile of toxicity and interactions, besides having a high genetic barrier to viral resistance, which causes the virus resistance to develop more slowly (8). While EFV has a favorable 
toxicity profile, leading to long-term suppression of viral replication (5), DTG does this same process within four weeks of treatment (21). The new drug increases the chance of viral suppression among adults by $42 \%$ compared to previous treatment using EFZ. Since this drug was recently incorporated in Brazil, there are no studies in the literature regarding its effect on the respiratory and peripheral muscle strength of patients submitted to this treatment.

\section{Methods}

We conducted a descriptive, longitudinal and prospective observational and analytical study that aimed to compare respiratory and peripheral muscle strength before and after more than 50 days of initiation of ART with Tenofovir / Lamivudine / Dolutegravir (TDF / 3TC / DTG). It was carried out with patients from a public outpatient clinic that offers referral treatment for HIV/AIDS in the city of Recife, the capital of the state of Pernambuco, an important medical center in Northeast Brazil. All ART-naive patients aged 18 to 60 years were eligible. The sample size calculation was performed based on the first Brazilian study (13) witch assessed pulmonary function in PLWHA, finding a 23\% prevalence of IMW and EMW in this population. Taking into account these observations, we used the program WinPep (22) and the following criteria were adopted: probable population of 120 patients, $95 \%$ confidence interval, totaling a minimum sample of 84 patients. However, the sample size was small due to the low average enrollment of antiretroviral-naive HIV-infected patients at the place of study and data collection period (between 4 and 5 patients per month). Thus, the recruitment was performed for convenience and consecutively and the screening through analysis of the medical records on the day before the medical appointment.

Evaluations were performed in two stages: T0 (before ARV use) and T1 (more than 50 days of ARVs). Those who were eligible and agreed to participate were included in the study after signing the informed consent form. Patients with active opportunistic infection, neuromuscular diseases, motor or cognitive sequelae, or who refused to participate in the study were excluded. Between the first and the second evaluation, the pulmonary function test was performed (through spirometry). For the second stage of the study, those who started ARV regimen other than TDF / 3TC / DTG, given up treatment, were transferred to another place of follow-up or refused to continue the study, and those who did not have time to perform the second evaluation were excluded from the study. 
At T0 were collected the clinical (time since diagnosis of HIV infection in the first evaluation), biological (gender and race) and socio-economic (schooling and employment) characteristics, lifestyle (physical activity and smoking), presence of a record of systemic arterial hypertension (SAH) and / or diabetes mellitus (DM), as well as anthropometric assessments (weight, height, body mass index), muscle strength (peripheral through dynamometry, and respiratory through manovacuometry), functional capacity (six-minute walk test - 6MWT) and pre-ART immune status (CD4 and CD8 count and VL).

Dynamometry, which measures HGS, is probably the most commonly used method for characterizing human muscle strength in general (23) and was assessed by the portable hydraulic dynamometer (New Saehan Squeeze Dynamometer - SH 5008) - MSD Europe ${ }^{\circledR}$ with the participant seated in an armless chair, feet flat on the floor and hip and knee positioned at approximately $90^{\circ}$ of flexion. . The shoulder of the tested limb adducted and in neutral rotation, $90^{\circ}$ flexed elbow, forearm in neutral position and wrist between 0 and $30^{\circ}$ of extension and between 0 and $15^{\circ}$ of adduction. The hand of the untested limb resting on the same thigh, as advocated by the American Society of Hand Therapists (ASHT) (24). Three measurements were obtained at one minute interval, the highest value was considered. Men with values below $30 \mathrm{kgf}$ and women below $20 \mathrm{kgf}$ were considered with dynapenia $(25,26)$.

Respiratory muscle strengths were assessed using an analog manovacuometer Murenas ${ }^{\circledR}$ $-120 /+120 \mathrm{cmH}_{2} \mathrm{O}$, which assessed maximal inspiratory pressure (MIP) and MEP following internationally recommended maneuvering patterns (27). Predictive values for maximal respiratory pressures (MIP and MEP in $\mathrm{cmH} 2 \mathrm{O}$ ) were calculated by adjusting gender and age using equations proposed in a previous study (28). The lower limit of each pressure was obtained by subtracting the value obtained by the regression equation for calculating the maximum respiratory pressures from the value obtained in the lower limit equation (LLE). The MIP and MEP results achieved by the subjects were considered normal when their values were within the range of the predicted and normal lower limit values, as adopted in a recent study on evaluation of respiratory function in PLWHA (13). Thus, we considered patients with IMW and / or EMW whose maximal respiratory muscle forces failed to reach the lower limit than predicted by the formula. 
Functional capacity was assessed by walking distance in the six-minute walk test (6MWD) following American Thoracic Society (ATS) standards (29). The expected 6MWD was calculated on the basis of proposed formulas in a previous study (30), which take into account gender, height, age and weight, and the results were expressed in meters. The maximum distance traveled was used to assess submaximal functional capacity and was written in meters $(\mathrm{m})$. Individuals who traveled the distance equal to or greater than expected, represented by the value obtained in the calculation of this formula, were considered to have satisfactory functional capacity. The test was performed twice, with a time interval of one hour between them, for learning purposes, which was considered the longest distance traveled between the two tests (29).

The immunological status of the patients was assessed by CD 4 and CD 8 counting, CD4/CD8 ratio, and viral load $(\mathrm{VL})$, performed from the fasting patient's blood collection, where the technique used to quantify CD4 and CD8 counting (expressed in cells / $\mathrm{mm}^{3}$ ) was Flow Cytometry / BD Multitest / Facscalibur, and VL (copies / mL) by the HIV 1 PCR RealTime technique.

Spirometry was performed according to ATS standards (31), using a digital spirometer (MicroQuark® spirometer, Cosmed - Italy), based on the theoretical values for the Brazilian population defined by previous study (32). Three to eight trials were performed until three acceptable and two reproducible curves were obtained. Forced Vital Capacity (FVC), Forced Expiratory Volume in one second (FEV1) and Tiffeneau Index (ratio of FEV1 and FVC) were measured, measurements recorded in absolute values and predicted percentages, and the reproducible maneuver with the highest FEV1 value was selected (31).

The revaluation at T1 was carried out in the same way as at T0, except for the general data. Only one 6MWT was performed at this time, as the patient already knew how to perform it. The TDF / 3TC / DTG regimen and treatment adherence were checked at the time of reevaluation, with sufficient adherence being taken at least $80 \%$ of the medication to achieve viral suppression and maintenance (5).

Statistical analyzes were performed using the Statistical Package for Social Science software SPSS - for Windows version 22.0 (IBM, Chicago, IL, EUA) and GraphPad Prism ${ }^{\circledR}$ version 7.00 for Windows. Descriptive (sample characterization) and inferential statistics techniques were employed, using parametric or nonparametric tests for data analysis, depending on their distribution. The Shapiro- 
Wilk test was applied for normality and the results presented as mean \pm standard deviation or median with interquartile range $(25 \%-75 \%)$, according to their distribution, as well as percentage values. Categorical comparisons were performed by Fisher's exact test and continuous comparisons by t-test or Wilcoxon test. Pearson or Spearman correlations, according to data normality, were performed to evaluate possible associations. The $p$-value $<0.05$ was considered significant for all analyzes.

The study was approved by the Institutional Research Ethics Committee (CEP-CCS-UFPE / 2.419.043).

\section{Results}

\section{Patients follow-up:}

Sixty-five patients were eligible, of which 24 were excluded (seven were younger than 18 years old, three were older than 60 years old, two had Ol, one had a neurological problem, 12 refused to participate in the study and five were not evaluated by the researcher). Thus, 41 patients were included for evaluation at T0. Of these, 23 performed spirometry, but one of them failed to reproduce acceptable and reproducible curves, even after eight attempts, thus not having their examination recorded for analysis. Respiratory disorder was found in one patient by analyzing the Tiffeneau Index, classifying it as mild obstructive disorder. There was a $36.6 \%$ loss of patients during the follow-up study (four started another ARV regimen, four refused to continue the study, one abandoned treatment, one was transferred to another medical center and three did not have time enough to perform the second assessment), so there were evaluated 28 patients in T1.

\section{Sample Characterization:}

In T0, 41 patients were evaluated, with a mean age of $31.6 \pm 6.5$ years, $80.5 \%$ male. Only $29.3 \%$ had tertiary education and almost $30 \%$ of participants were unemployed. Regarding the practice of regular physical activity $76 \%$ of the patients reported physical inactivity, $39 \%$ were overweight and $15 \%$ with controlled hypertension, and most denied the habit of smoking. Patients who were reevaluated 
reported not having changed habits such as physical activity and smoking. Table 1 summarizes these findings.

Table 1. Biological, socioeconomic characteristics, comorbidities, pulmonary function, muscle strength, functional capacity of 41 Antiretroviral-Naive HIV-Infected Patients 


\begin{tabular}{|c|c|}
\hline Variables & $\begin{array}{l}\text { TOTAL } \\
\mathbf{n}=41\end{array}$ \\
\hline Age (years) Mean \pm SD & $31.6( \pm 6.5)$ \\
\hline \multicolumn{2}{|l|}{ Gender n (\%) } \\
\hline Male & $33(80.5 \%)$ \\
\hline Female & $8(19.5 \%)$ \\
\hline \multicolumn{2}{|l|}{ Race n (\%) } \\
\hline White & $6(14.6 \%)$ \\
\hline Black/Brown & $35(85.4 \%)$ \\
\hline \multicolumn{2}{|l|}{ Educational Status n (\%) } \\
\hline Unlettered & $2(4.9 \%)$ \\
\hline Incomplete Elementary & $6(14.6 \%)$ \\
\hline Complete Elementary & $7(17.1 \%)$ \\
\hline Complete High School & $14(34.1 \%)$ \\
\hline Incomplete High school & $5(12.2 \%)$ \\
\hline Higher Education Complete & $7(17.1 \%)$ \\
\hline \multicolumn{2}{|l|}{ Employment Bond n (\%) } \\
\hline Yes & $13(31.7 \%)$ \\
\hline No & $16(39 \%)$ \\
\hline Unemployed & $12(29.3 \%)$ \\
\hline \multicolumn{2}{|l|}{ Body Mass Index $\mathrm{kg} / \mathrm{m}^{2}$} \\
\hline Underweight (< 18.5) & $2(4.9 \%)$ \\
\hline Normal weight $(\geq 18,5$ and $<25$ ) & $23(56.1 \%)$ \\
\hline Overweight ( $\geq 25$ and $<30$ ) & $9(22 \%)$ \\
\hline Obesity $(\geq 30)$ & $7(17 \%)$ \\
\hline \multicolumn{2}{|l|}{ Physical activity practice } \\
\hline Yes & $10(24.4 \%)$ \\
\hline No & $31(75.6 \%)$ \\
\hline Smoking status & \\
\hline
\end{tabular}




\begin{tabular}{|c|c|}
\hline Yes & $15(36.6 \%)$ \\
\hline No & $21(52.2 \%)$ \\
\hline Former smoker & $5(11.2 \%)$ \\
\hline \multicolumn{2}{|l|}{ Systemic arterial hypertension (SAH) } \\
\hline Yes & $6(14.6 \%)$ \\
\hline No & $35(85.5 \%)$ \\
\hline \multicolumn{2}{|l|}{ Diabetes mellitus (DM) } \\
\hline Yes & $1(2.4 \%)$ \\
\hline No & $40(97.6 \%)$ \\
\hline \multicolumn{2}{|c|}{ Time of diagnosis of HIV infection at first assessment } \\
\hline Less than 6 months & $34(82.3 \%)$ \\
\hline 6 months or more & $7(17.7 \%)$ \\
\hline \multicolumn{2}{|l|}{ PLWHA } \\
\hline With AIDS & $16(39 \%)$ \\
\hline Without AIDS & $25(61 \%)$ \\
\hline \multicolumn{2}{|l|}{ Pulmonary Function ${ }^{(*)}$} \\
\hline FVC & $4,7( \pm 0.5)$ \\
\hline FVC (\%) & $100,5( \pm 8.9)$ \\
\hline $\mathrm{FEV}_{1}$ & $3,8( \pm 0.5)$ \\
\hline $\mathrm{FEV}_{1}(\%)$ & $100,1( \pm 8.9)$ \\
\hline $\mathrm{FEV}_{1} / \mathrm{FVC}$ & $84,3( \pm 5)$ \\
\hline $\mathrm{FEV}_{1} / \mathrm{FVC}(\%)$ & $103,5( \pm 5.9)$ \\
\hline \multicolumn{2}{|l|}{ Muscle strength } \\
\hline $\mathrm{MIP} \mathrm{cmH}_{2} \mathrm{O}$ & $120(100-120)$ \\
\hline MEP $\mathrm{cmH}_{2} \mathrm{O}$ & $120(106-120)$ \\
\hline HGS Kgf & $16(12.75-19)$ \\
\hline Functional capacity - 6MWD meters & $585(526.5-644)$ \\
\hline
\end{tabular}


Values are expressed as frequency (\%), mean ( \pm standard deviation) or median (interquartile value $25 \%-75 \%)$. SAH and DM: diagnosis reported by the individual; HIV: Human Immunodeficiency Vírus. PLWHA: People living with HIV / AIDS. FVC: Forced Vital Capacity; FVC (\%): percentage of expected FVC; FEV 1 : Forced expiratory volume in one second; FEV 1 (\%): percentage of predicted $\mathrm{FEV}_{1} ; \mathrm{FEV}_{1} / \mathrm{FVC}$ : Tiffeneau Index; FEV 1 /FVC (\%): percentage of predicted FEV1 / FVC. MIP: Maximal inspiratory pressure; MEP: Maximal expiratory pressure; HGS: handgrip strength. 6MWD: six-minute walk test distance. ${ }^{\left({ }^{*}\right.}$ Evaluated data from 22 patients.

\section{Laboratory markers}

Information on pre-ART immunological status (laboratory outcome of CD4, CD8 and VL) was available for 37 (90.2\%) patients, with a mean CD4 $462.9 \pm 230.8$ cells / $\mathrm{mm}^{3}$, and minimum viral load of 104 and maximum of 1999822 copies / mL. Of the patients with AIDS-defining illness, seven (43.8\%) had moderate immunodepression (CD4 between 201 and 349 cells / mm3) and nine (56.2\%) severe immunodepression (CD4 less than 200 copies / mm³). All patients had a subnormal CD4 / CD8 ratio (less than one) and detectable VC, where nine (22\%) had high HIV-VC (above 100,000 copies / mL). A total of nine patients (21.9\%) had late onset of ARV treatment (refers to the initiation of treatment with the patient having CD $4<200$ cells / $\mathrm{mm}^{3}$ or presence of AIDS-defining illness) (33).

Of the 28 patients reassessed at T1, six (21.4\%) had no LT-CD4 and / or VL results. After more than 50 days of ART, three (10.7\%) had improved immune response (CD4 / CD8 ratio greater than one) and 18 (64.3\%) patients had maximum viral suppression (undetectable VL).

\section{Muscle strength and functional capacity}

From the total sample evaluated at T0, one patient did not show a reduction in HGS and two underwent the predicted 6MWD. There was a positive correlation between CD4 and HGS $(p=0.027)$ and a negative correlation between HGS and VL $(p=0.046)$ as described in table 2. 
Table 2. Correlation between CD4 and Viral load and Inspiratory and Expiratory muscles strengths, Peripheral muscle strength and Six-Minute Walk Test Distance in 41 Antiretroviral-Naive HIV-Infected Patients

\begin{tabular}{lcccc}
\hline VARIABLE & \multicolumn{2}{c}{ CD4 } & \multicolumn{2}{c}{ VIRAL LOAD } \\
\cline { 2 - 5 } & $r$ & $p$-value* & $r$ & $p$-value* \\
\hline MIP & -0.54 & 0.739 & -0.173 & 0.293 \\
MEP & 0.292 & 0.064 & -0.326 & 0.050 \\
HGS & 0.346 & $\mathbf{0 . 0 2 7}$ & -0.321 & $\mathbf{0 . 0 4 6}$ \\
6MWD & 0.68 & 0.673 & -0.057 & 0.732 \\
\hline
\end{tabular}

* Spearman correlation. The values in bold denote statistical difference. MIP: Maximal inspiratory pressure; MEP: Maximal expiratory pressure; HGS: handgrip strength. 6MWD: six-minute walk test distance.

Prior to initiation of treatment for viral suppression, 40 (97.6\%) patients had dynapenia and 13 (31.7\%) had MIP and / or MEP below the expected value. When stratified in relation to the presence of RMW (inspiratory and expiratory muscle weakness) there was no significant correlation with CD4 and CD8 count, CD4/CD8 ratio and VL, as analyzed in Tables 3 and 4.

Table 3. Relationship between laboratory data (CD4, CD8, CD4 / CD8, HIV CV count) and Inspiratory muscle weakness in 41 Antiretroviral-Naive HIV-Infected Patients

\begin{tabular}{lcccc}
\hline & & \multicolumn{3}{c}{ Inspiratory Muscle Weakness } \\
\cline { 3 - 5 } VARIABLE & TOTAL & YES & NO & $p$-value* \\
\hline CD4 & $462.9 \pm 230.8$ & $522.9 \pm 308.5$ & $448.4 \pm 283.4$ & 0.548 \\
CD8** & $119.2 \pm 563.1$ & $912.5 \pm 633.4$ & $1273.1 \pm 699.5$ & 0.187 \\
\hline CD4/CD8** & $0.4 \pm 0.2$ & $0.5 \pm 0.2$ & $0.4 \pm 0.3$ & 0.373 \\
\hline Viral Load*** & $172062.9 \pm 219876.9$ & 387996 & $124827.5 \pm 309428.9$ & 0.384 \\
& & \pm 309428.9 & & \\
\hline
\end{tabular}


*T-Test. Variables are expressed as mean \pm standard deviation; CD4 and CD8 count expressed in cells / $\mathrm{mm}^{3}$ of blood; Viral load expressed in copies / $\mathrm{mL}$ of blood. ** analysis performed with 38 individuals; *** analysis performed with 40 individuals.

Tabela 4. Relationship between laboratory data (CD4, CD8, CD4 / CD8, HIV CV count) and Expiratory muscle weakness in 41 Antiretroviral-Naive HIV-Infected Patients

\begin{tabular}{lcccc}
\hline & & \multicolumn{3}{c}{ Expiratory Muscle Weakness } \\
\cline { 3 - 5 } VARIABLE & TOTAL & YES & NO & $p$-value* \\
\hline CD4 & $462.9 \pm 230.8$ & $423.3 \pm 321.8$ & $475.7 \pm 278.1$ & 0.651 \\
& & & & \\
CD8** & $119.2 \pm 563.1$ & $942.7 \pm 557.2$ & $1288.1 \pm 723.8$ & 0.137 \\
\hline CD4/CD8** & $0.4 \pm 0.2$ & $0.5 \pm 0.2$ & $0.4 \pm 0.3$ & 0.775 \\
\hline Viral Load*** & $172062.9 \pm 219876.9$ & $105520.2 \pm 158300$ & $192025.7 \pm 467181.5$ & 0.394 \\
\hline
\end{tabular}

*T-Test. Variables are expressed as mean \pm standard deviation; CD4 and CD8 count expressed in cells / mm of blood; Viral load expressed in copies / $\mathrm{mL}$ of blood. ** analysis performed with 38 individuals; *** analysis performed with 40 individuals

When respiratory and peripheral muscle strengths were compared before and after more than 50 days of ART treatment, there was an increase in both MIP $(p=0.0176)$ and HGS $(p=0.0018)($ Table 6).

Table 6. Inspiratory and expiratory muscle strength, peripheral muscle strength, and functional capacity in 28 people living with HIV/AIDS evaluated before and after more than 50 days of ART. 


\begin{tabular}{lccc}
\hline \multirow{2}{*}{ VARIABLE } & T0 $(n=41)$ & T1 $(n=28)$ & $p$-value* \\
\cline { 2 - 4 } MIP Md (25-75\%) & $120(100-120)$ & $120(120-120)$ & 0.0176 \\
MEP Md (25-75\%) & $120(106-120)$ & $120(108-120)$ & 0.9336 \\
\hline HGS & $16(12.75-19)$ & $18(15-20.25)$ & 0.0018 \\
\hline 6MWD & $585(526.5-644)$ & $600(547.8-655.5)$ & 0.8957 \\
\hline
\end{tabular}

* Wilcoxon test; Values are expressed as median (interquartile value $25 \%-75 \%$ ). Values in bold denote statistical difference. ART: antiretroviral therapy. MIP: Maximal inspiratory pressure; MEP: Maximal expiratory pressure; HGS: handgrip strength. 6MWD: sixminute walk test distance.

\section{Discussion}

This may be the first attempt to evaluate the effect of TDF / 3TC / DTG-based ARV regimen on the respiratory and peripheral muscle strength of PLWHA in treatment against HIV infection.

The sample evaluated consisted of $80.5 \%$ of men, a percentage higher than that reported by the latest HIV / AIDS epidemiological newsletter released by the Brazilian Ministry of Health (34), where it showed new cases of HIV infection of $68.6 \%$ in males. Regarding education, $65.9 \%$ of the subjects had studied until the end of high school. In addition, Brazil has been showing a reduction in the annual number of AIDS cases since 2013, however, the North and Northeast regions showed a growing trend in detection and in our study we detected the frequency of $39 \%$ of cases.

Most of our sample reported physical inactivity, and those who practiced physical activity maintained their activities during the period between $\mathrm{T} 0$ and $\mathrm{T} 1$, so this factor should not have influenced the outcomes of the outcomes found in our study. Those who were physically active had better muscle strength scores when compared to sedentary ones. A reasonable explanation for the association between HGS and inflammation is that muscle mass is a predictor of higher HGS and those who practice regular 
exercise tend to have higher muscle mass (35). Moreover, only $39 \%$ of the subjects were overweight. It is worth considering that, although the association between $\mathrm{BMI}$ and muscle strength was not measured in the present study, changes in body fat in PLWHA are associated with increased systemic inflammation and increased mortality (36).

The high prevalence of smoking among PLWHA is known when compared to the general population (5). Our sample consisted of $47.8 \%$ smokers and / or former smokers, although there was a presence of respiratory disorder in only one $(4.3 \%)$ of the patients submitted to pulmonary function test. Emerging data suggest that there is a $34 \%$ prevalence of respiratory changes in PLWHA in the pre-ART era (37), although we have not identified this relationship in our data set. We believe the small size of our sample may not have represented reality. On the other hand, it is believed that the timing of ART initiation has no significant short-term effect on the rate of lung function decline in HIV-positive individuals with CD4 above 500 cells / $\mathrm{mm}^{3}$ and antiretroviral-naive HIV-infected patients (38).

Our results showed that almost $80 \%$ of patients started treatment within six months of being diagnosed with HIV infection. In this regard, antiretroviral-naive HIV-infected patients are the leading source of drug-resistant viruses in developed countries. Moreover, phylogenetic findings have suggested that proliferation of infected cells prior to initiation of ART would be primarily responsible for residual viremia (39). This sustained viral replication promotes an immune / inflammatory response that cannot be reversed after a certain point. Given the relationship between inflammation and declining functional performance in PLWHA, regardless of age (36), the beginning of ARV treatment before reaching this point may prevent the state of persistent inflammation and immune activation by decreasing CD8 and monocyte - macrophage activation, supporting the hypothesis that activation of these cells could be reversed to levels normal with early ARTs (7), avoiding, then, the loss of functionality in this population.

Besides that, the above studies confirm the findings detected in the HIV-infected African population, which suggests that virus infection alone does not have adverse effects on HGS, but rather the effects of untreated HIV and systemic inflammation leading to accelerated loss of lean mass and metabolic imbalances, leading to the reduction of HGS, thus accelerating the process of fragility (40). Not less important, the normalization of PLWHA immune status is also a favorable outcome of HIV / AIDS treatment. An increase in CD4 count to 500 cells $/ \mathrm{mm}^{3}$ or higher during ART is usually considered as 
optimal immune recovery. It has been verified that the postponing initiation of ART after more than 12 months of estimated date of seroconversion (passage from the first phase of HIV infection to the second, the latency phase), decreases the probability of restoring immune health in HIV-1 infected individuals $(41,42)$.

The assessment of HGS has a good correlation with measurements of muscle function, such as knee extension and peak forced expiratory volume (43) besides being able to predict both death and disease from vascular causes (44). In this context, it is worth to alarming the results of our study, where $97.6 \%$ of PLWHA had dynapenia before the beginning of ART, in contrast to the $15.4 \%$ found in the first study conducted in Brazilian Northeast evaluating the functional profile of PLWHA before treatment (37). Despite having recorded values of $V L$ of the evaluated individuals, there was no description of this variable in the results, only of CD $4\left(403 \pm 284 \mathrm{cel} / \mathrm{mm}^{3}\right)$, a value lower than that recorded in our study ( $462.9 \pm 230.8$ cells $/ \mathrm{mm} 3$ ). Thus, we believe that the high frequency of HGS below the predicted value found in our study is related to the high viremia of our population (172062.9 \pm 219876.9 copies $/ \mathrm{mL}$ ), configuring systemic inflammatory status. This finding is in line with that obtained in the abovementioned study, suggesting that HIV infection plays a role in promoting dynapenia in untreated patients. Likewise, it should be considered that men and women may react differently to HIV infection and ART use, so women may have less muscle strength than men (45), as found in a previous study (37). Our analyzes were not stratified by gender, as only $19.5 \%$ of our sample consisted of women.

Some authors believe that in PLWHA systemic biochemical abnormalities may occur, resulting in inspiratory muscle dysfunction, with weakness of this musculature (12). The initial evaluation of our study found that $31.7 \%$ of patients had IMW and / or EMW, with lower than expected MIP and MEP values, respectively. MEP is intrinsically linked to respiratory muscle capacity, and reduced values of this pressure imply various physical and pulmonary conditions, including neuromuscular disorders (13).

In the light of the results of previous studies, which indicated that HGS measurements would not be an adequate substitute for well-controlled clinical performance testing in PLWHA. (46), we performed the $6 \mathrm{MWT}$ assessment in order to obtain more robust data regarding the functional capacity of this population. In the evaluation performed before starting treatment for infection, $95.12 \%$ of the subjects did not reach the predicted 6MWD, corroborating a study in antiretroviral-naive HIV-infected patients, which 
also found lower than expected 6MWD values in both genders (37). Our results also support those obtained in a study conducted with PLWHA, which observed an influence of CD4 lower than 200 cells / $\mathrm{mm}^{3}$ on inspiratory muscle strength and 6MWD (12). Like these authors, we agree that this is happens due to HIV infection, because the patients in our study had high viremia at the time of the first assessment, and HIV alone could have a negative influence on functional capacity in these individuals. It is also noteworthy that the high frequency of dynapenia may explain non-compliance with the 6MWD, as reduced muscle strength may contribute to the feeling of fatigue and functional limitation (47).

Of the PLWHA evaluated at T0, $61 \%$ had no immunosuppression, in other words, had CD4 count above 350 copies / $\mathrm{mm}^{3}$, and this showed a positive correlation with HGS. So all patients without compromised immune system presented higher values of HGS. These findings contradicted those found in the Multicenter AIDS Cohort Study (MACS) substudy (36), an American cohort that evaluated for 30 years (1994-2014) a large population of HIV-infected gay and bisexual men, where no association was found between HGS and current CD4 or nadir CD4. Additionally, another study conducted in Africa also found no independent effects between CD4 count and HGS in a cross-sectional analyzes (40). On the other hand, considering that a previous study found concentrations of Interferon Gamma-Induced Protein 10 (IP-10), an immune activation biomarker, associated with low CD4 levels (48), we suggest that the best HGS values found in the higher CD4 patients would be due to the lower inflammatory status in these patients. However, due to the absence of inflammation markers collection at the time of the evaluations, we cannot conclude the existence of this association.

HGS values obtained in the evaluation before the initiation of ART showed a negative correlation with VL. In this way, lower HGS values correlated with high levels of VL. Given these observations, we hypothesized that this reduction in HGS would be associated with the inflammatory status caused by high viremia. This hypothesis is supported by a previous study, which found a relationship between IP-10 concentrations with high VL, even suggesting that this biomarker may be associated with HIV pathogenesis and immune depletion (48). In addition, our findings also corroborate those found in the substudy, suggesting that VL cumulative increased exposure seems to be an important factor in the decline in HGS, and further highlights the importance of early initiation of ART (14). 
Considering reduction in muscle strength may contribute to the feeling of fatigue and functional limitation (47), HGS provides data not available from routine clinical and laboratory evaluations. Thus, the measurement of this variable during follow-up with the infectologist may provide additional information for risk stratification during the evaluation of outpatient PLWHA.

In our study, the frequency of RMW in antiretroviral-naive HIV-infected patients was greater than $30 \%$, however, this weakness did not correlate with CD4 and CD8 count, CD4/CD8 ratio, and VL. This results may have been influenced by the small sample size. MIP measurement is earlier than changes in lung volume to diagnose inspiratory weakness. MEP has a low accuracy to predict coughing capacity, as it generates a high false positive index for EMW, and may overestimate the number of patients with EMW, since low values are caused by submaximal efforts or leakage around the mouthpiece, which is frequent in patients with facial muscle weakness. Both depend on the coordination between the evaluated and the examiner, so a low value may not mean weakness, but lack of collaboration of the evaluated subject (49). We believe that this did not interfere with the results of our study, since $65.9 \%$ of the sample had a medium level of education, having completed at least high school, obtaining a good understanding of the commands given to perform the tasks evaluations, besides that the vast experience of the examniner's in such evaluations.

Newer medications tend to cause less mitotoxicity. Thus, the incidence of this toxicity may be decreasing even as more patients are submitted to treatment with Reverse Transcriptase Nucleoside Inhibitors (NTRs) such as Tenofovir and Lamivudine (50). Furthermore, studies indicate that DTG is a useful drug in terms of rapid virologic suppression in patients with good treatment adherence (21), showing superiority over the previous regiment containing EFZ Our results showed a significant increase in MIP and HGS after more than 50 days of ART, presumably through control of viral replication and subsequent reduction of inflammation and immune activation, as more than $80 \%$ of patients progressed to undetectable VL in this period. This effect is hypothesized to be mediated by ART's ability to reduce inflammation, immune activation, and endothelial dysfunction by suppressing HIV replication (7). Conclusive findings in previous research support our theory. The English Longitudinal Study of Ageing (ELSA), conducted in England with an eight-year follow-up showed that higher HGS would be associated with lower levels of inflammation (35). In another interesting study of hospitalized patients with and without TB, proved that higher levels of Tumor Necrosis Factor Alpha (TNF-a) but not Interleukin-6 (IL-6) 
were associated with a reduction in MIP, MEP and HGS (47). In addition, previous study data pointed out that HGS appears to steadily increase over time for ART in men, although it has stabilized after the first 12 weeks of treatment in women (40), corroborating with our findings.

Notably, the loss of $36.6 \%$ of patients during follow-up associated with the short interval between evaluations denotes a major limitation of our study. The loss to follow-up of HIV infected patients is a problem that is frequently reported on in the literature (51) and even registered in the HIV-Brazil Cohort, with the highest proportion of loss (50.4\%) in the first year of follow-up, identifying the Northeast as the second largest region of loss of follow-up of patients (52). The fact that we conducted our study at a single state referral center for HIV treatment may have caused some bias. Similarly, the decrease in sample size over time limits our statistical power, although it is highly relevant, since most patients had dynapenia, even without major functional impairment. We found important, although weak, correlations between HGS and CD4 count and VL, but the lack of collection of immune activation markers such as IL6, TNF- $a$ and C-reactive protein (CRP) at T0 and T1 prevented the analysis of the inflammatory status of the patients at the time of the evaluation and it was not possible to establish a causal relationship between these variables. The instrument used to evaluate MIP and MEP, the analog manovacuometer, was limited to maximal pressures of $120 \mathrm{cmH}_{2} \mathrm{O}$ and could have underestimated our results. However, the cost, availability, and ease of use may determine whether the techniques are best suited to clinical practice or useful for research (26). In this context, we chose to use a lower cost instrument in order to try to reproduce as much as possible the reality of the public hospital service.

Considering these observations, it is worth highlighting that this is the first study to evaluate the association between HGS and CD4 count and VL, as well as the effect of ART combined with TDF / 3TC / DTG on PLWHA musculature. Longitudinal studies with longer follow-up time allow a more accurate assessment, establishing a causal relationship.

\section{Conclusions}

The findings of this research showed impairment in overall functional capacity and high frequency of dynapenia in PLWHA before the onset of ARVs, and that HGS was directly correlated with CD4 count 
and inversely correlated with VL. In addition, there was an increase in MIP and HGS after more than 50 days of HIV treatment. Future studies are needed to better understand the effect of TDF/3TC/DTG combined ART on the respiratory and peripheral muscle strength of PLWHA under treatment, and may contribute to the implementation of systematic outpatient muscle strength assessment of these patients in an attempt to early diagnose the functional injury of these individuals, allowing them to be referred to an appropriate rehabilitation service, in order to avoid hospitalizations for respiratory infections resulting from the loss of the respiratory muscles.

\section{Abbreviations}

3TC: Lamivudine; 6MWD: Six-minute walk test distance; 6MWT: Six-minute walk test; AIDS: Acquired Immunodeficiency Syndrome; ART: antiretroviral therapy; ARVs: antiretrovirals; ASHT: American Society of Hand Therapists; ATS: American Thoracic Society; CRP: C-reactive protein; DM: Diabetes mellitus; DTG: Dolutegravir; EFV: Efavirenz; ELSA: English Longitudinal Study of Ageing; EMW: Expiratory muscle weakness; FEV1: Forced Expiratory Volume in one second; FEV1/FVC: Tiffeneau Index; FVC: Forced Vital Capacity; HGS: handgrip strength; HIV: Human Immunodeficiency Virus; IL-6: Interleukin-6; IMW: Inspiratory muscle weakness; IP-10: Interferon Gamma-Induced Protein 10; LLE: Lower limit equation; MACS: Multicenter AIDS Cohort Study; mtDNA: mitochondrial deoxyribonucleic acid; Ols: Opportunistics infeccions; MEP: Maximal expiratory pressure; MIP: Maximal inspiratory pressure; NTRs: Reverse Transcriptase Nucleoside Inhibitors; PLWHA: People living with HIV / AIDS; RMW: Respiratory muscle weakness; SAH: Systemic arterial hypertension; T0: before the initiation of antiretroviral therapy; T1: after more than 50 days of treatment; TDF: Tenofovir; TDF/3TC/DTG: Tenofovir/Lamivudine/Dolutegravir ART scheme; TNF-a: Tumor Necrosis Factor Alpha; VL: Viral load.

\section{Declarations}

\section{Ethics approval and consent to participate}


The study was approved by the Institutional Research Ethics Committee (CEP-CCS-UFPE / 2.419.043) for the publication of this work. Free and informed consent was obtained from all participants. A copy of the written consent of the ethics committee of the Federal University of Pernambuco is available for review by the chief editor of this journal. The authors declare that the procedures followed the regulations established by the local ethics committee of the Federal University of Pernambuco. All records remain confidential and kept by the corresponding author.

\section{Consent for publication}

Not applicable.

\section{Availability of data and materials}

The data supporting the results of this study are in the possession of the corresponding author, but as restrictions apply the availability of these data, which were used under license for the current study and are therefore not publicly available. However, data are available from the authors upon reasonable request and permission of the Federal University of Pernambuco.

\section{Competing interests}

The authors have no potential competing interest regarding the research, authorship and / or publication of this article.

\section{Funding}

Nonexistent.

\section{Authors' contributions}


ROC performed data collection (muscle strength and maximal functional capacity assessments). JBM and PSRA contributed to the design of the study, critically revised the manuscript. MAVCJ performed data analysis. ELC performed the evaluation of the pulmonary function of the patients. ROC and PSRA are accountable for all aspects of the work in ensuring that questions related to the accuracy or integrity of any part of the work are appropriately investigated and resolved. All authors approved the version being published.

\section{Acknowledgement}

For patients who make a participation in this research available, where they often sacrifice themselves for it, can be realized.

\section{Authors' information}

${ }^{1}$ Center for Health Sciences, Federal University of Pernambuco - UFPE, Recife, PE - Brazil.

${ }^{2}$ Pernambuco Cancer Hospital - HCP

${ }^{3}$ Department of Physical Education and Hebiatrics, University of Pernambuco - UPE, campus Recife, PE -

Brazil

${ }^{4}$ Department of Tropical Medicine - UFPE.

${ }^{5}$ Aggeu Magalhaes Institute - Oswaldo Cruz Foundation

\section{References}

1. UNAIDS. UNAIDS DATA 2019. 2019;

2. Touw M. Update on Human Immunodeficiency Virus. Physician Assist Clin [Internet]. 2017;2(2):327-43. Available from: http://dx.doi.org/10.1016/j.cpha.2016.12.013

3. Brites C. Inflamação e coagulação em pacientes infectados pelo HIV-1. Educ médica Contin - BJID. 2016;2(4):118-23. 
4. Maagaard A, Kvale D. Mitochondrial toxicity in HIV-infected patients both off and on antiretroviral treatment: A continuum or distinct underlying mechanisms? J Antimicrob Chemother. 2009;64(5):901-9.

5. Ministério da Saúde. Protocolo Clínico e Diretrizes Terapêuticas para Manejo da Infecção pelo HIV em Adultos [Internet]. Secretaria de Vigilância em Saúde. Departamento de Vigilância, Prevenção e Controle das Infecções Sexualmente Transmissíveis, do HIV/Aids e das Hepatites Virais. Protocolo. 2018. 412 p. Available from: http://www.aids.gov.br/ptbr/pub/2013/protocolo-clinico-e-diretrizes-terapeuticas-para-manejo-da-infeccao-pelo-hiv-em-adultos

6. Montaner JSG, Lima VD, Harrigan PR, Lourenço L, Yip B, Nosyk B, et al. Expansion of HAART coverage is associated with sustained decreases in HIV/AIDS morbidity, mortality and hiv transmission: The "HIV treatment as prevention" experience in a Canadian setting. PLoS One. 2014;9(2):1-10.

7. Beltran LM, Rubio-Navarro A, Puig J, Amaro-Villalobos MJ, Egido J, García-Puig J, et al. Influence of immune activation and inflammatory response on cardiovascular risk associated with the human immunodeficiency virus. Vasc Health Risk Manag. 2015;35.

8. Bernal F. Farmacología De Los Antirretrovirales. Rev Médica Clínica Las Condes [Internet]. 2016;27(5):682-97. Available from: https://linkinghub.elsevier.com/retrieve/pii/S0716864016300943

9. Mbada CE, Onayemi O, Ogunmoyole Y, Johnson OE, Akosile CO. Health-related quality of life and physical functioning in people living with HIV/AIDS: a case-control design. Health Qual Life Outcomes [Internet]. 2013;11(JUNE):106. Available from: http://www.ncbi.nlm.nih.gov/pubmed/23802924\%5Cnhttp://www.pubmedcentral.nih.gov/articlerender.fcgi?artid=PMC3698161

10. Calza L, Danese I, Colangeli V, Vandi G, Manfredi R, Girometti N, et al. Skeletal muscle toxicity in HIV-1-infected patients treated with a raltegravir-containing antiretroviral therapy: a cohort study. AIDS Res Hum Retroviruses [Internet]. 2014;30(12):1162-9. Available from: http://www.ncbi.nlm.nih.gov/pubmed/25369244

11. Madeddu G, Socio GVL De, Ricci E, Quirino T, Orofino G, Carenzi L, et al. Muscle symptoms and creatine phosphokinase elevations in patients receiving raltegravir in clinical practice: Results from the SCOLTA project long-term surveillance. Int $\mathrm{J}$ Antimicrob Agents. 2014;45(3):289-94.

12. Jerônimo FS, Alves GN, Cipriano Jr. G, Vieira PJC, Güntzel AM, Chiappa GR. Factors associated with inspiratory muscle weakness in patients with HIV-1. Brazilian J Infect Dis. 2015;19(1):1-7.

13. Morsch Passos Al, Couto ER, Rezende SM De, Moretti ML. Evaluation of Functional Respiratory Parameters in AIDS Patients Assisted in the Infectious Diseases Ambulatory Care Clinic of a Tertiary Care University Hospital in Brazil. Respir Care. 2012;57(4):544-9.

14. Schrack JA, Jacobson LP, Althoff KN, Erlandson KM, Jamieson BD, Koletar SL, et al. Effect of HIV-Infection and Cumulative Viral Load on Age-Related Decline in Grip Strength. AIDS. 2016;30(17):2645-52.

15. Irwin RS, Boulet L-P, Cloutier MM, Fuller R, Gold PM, Hoffstein V, et al. Managing Cough as a Defense Mechanism and as a Symptom. A Consensus Panel Report of the American College of Chest Physicians. Chest. 1998;114(2):133S-181S.

16. SOUSA AIA., PINTO JUNIOR VL. Carga viral comunitária do HIV no Brasil , 2007 - 2011 : potencial impacto da terapia antirretroviral ( HAART ) na redução de novas infecções. Rev bras epidemiol. 2016;19(3):582-93. 
17. Presti RM, Flores SC, Palmer BE, Atkinson JJ, Lesko CR. Mechanisms Underlying HIV-Associated Noninfectious Lung Disease. Chest [Internet]. 2017;1-8. Available from: http://dx.doi.org/10.1016/j.chest.2017.04.154

18. Lake JE, Currier JS. Metabolic disease in HIV infection. Lancet Infect Dis [Internet]. 2013;13(11):964-75. Available from: http://dx.doi.org/10.1016/S1473-3099(13)70271-8

19. Payne BAI, Hollingsworth KG, Baxter J, Wilkins E, Lee V, Price DA, et al. In vivo mitochondrial function in HIV-infected persons treated with contemporary anti-retroviral therapy: A magnetic resonance spectroscopy study. PLoS One. 2014;9(1).

20. Ministério da Saúde. Nota Informativa 007 - protocolo de uso ARV - 2017 [Internet]. 2017 [cited 2017 Sep 19]. p. 1-6. Available from: http://azt.aids.gov.br/documentos/siclom_operacional/Nota Informativa 007 - protocolo de uso ARV - 2017.pdf

21. Todd S, Rafferty P, Walker E, Hunter M, Dinsmore W, Donnelly C, et al. Early clinical experience of dolutegravir in an HIV cohort in a larger teaching hospital. Int J STD AIDS [Internet]. 2017;28(11):1074-81. Available from: http://journals.sagepub.com/doi/10.1177/0956462416688127

22. Abramson JH. WINPEPI ( PEPI-for-Windows ): computer programs for epidemiologists. 2004;10:1-10.

23. Bohannon RW, Wang YC, Yen SC, Grogan KA. Handgrip Strength: A Comparison of Values Obtained From the NHANES and NIH Toolbox Studies. Am J Occup Ther Off Publ Am Occup Ther Assoc. 2019;73(2):1-9.

24. Severijns D, Lamers I, Kerkhofs L, Feys P. Hand grip fatigability in persons with multiple sclerosis according to hand dominance and disease progression. J Rehabil Med. 2015;47(2):154-60.

25. Schlüssel MM, dos Anjos LA, de Vasconcellos MTL, Kac G. Reference values of handgrip dynamometry of healthy adults: A population-based study. Clin Nutr. 2008;27(4):601-7.

26. Cruz-Jentoft AJ, Baeyens JP, Bauer JM, Boirie Y, Cederholm T, Landi F, et al. Sarcopenia: European consensus on definition and diagnosis. Age Ageing. 2010;39(4):412-23.

27. Black LF, Hyatt RE. Maximal respiratory pressures: normal values and relationship to age and sex. Am Rev Respir Dis. 1969;99:696-702.

28. Neder JA, Andreoni S, Lerario MC, Nery LE. Reference values for lung function tests. II. Maximal respiratory pressures and voluntary ventilation. Brazilian J Med Biol Res. 1999;32(6):719-27.

29. Crapo RO, Casaburi R, Coates AL, Enright PL, MacIntyre NR, McKay RT, et al. ATS statement: Guidelines for the six-minute walk test. Am J Respir Crit Care Med. 2002;166(1):111-7.

30. ENRIGHT, Paul L; SHERRILL DL. Reference Equations for the Six-Minute Walk.pdf. Am J Respir Crit Care Med. 1998;158(6):1384-7.

31. Miller MR, Hankinson J, Brusasco V, Burgos F, Casaburi R, Coates A, et al. Standardisation of spirometry. Eur Respir J. 2005;26(2):319-38.

32. Pereira CADC, Sato T, Rodrigues SC. New reference values for forced spirometry in white adults in Brazil. J Bras Pneumol. 2007;33(4):397-406.

33. Pacheco PRG, Zara ALSA, Silva E Souza LC, Turchi MD. Late Onset of Antiretroviral Therapy in Adults Living with HIV in an Urban Area in Brazil: Prevalence and Risk Factors. J Trop Med. 2019;2019.

Page 24/26 
34. Ministério da Saúde. Boletim Epidemiológico: HIV/AIDS. Brasília [Internet]. 2018; Available from: http://www.aids.gov.br/ptbr/pub/2018/boletim-epidemiologico-hivaids-2018

35. Smith L, Yang L, Hamer M. Handgrip strength, inflammatory markers, and mortality. Scand J Med Sci Sport. 2019; (January):1190-6.

36. Crawford KW, Li X, Xu X, Abraham AG, Dobs AS, Margolick JB, et al. Lipodystrophy and Inflammation Predict Later Grip Strength in HIV-Infected Men: The MACS Body Composition Substudy. AIDS Res Hum Retroviruses [Internet]. 2013;29(8):1138-45. Available from: http://www.liebertpub.com/doi/10.1089/aid.2013.0020

37. Lédo AP, Rodriguez-Prieto I, Lins L, Neto MG, Brites C. Association Between Health-Related Quality of Life and Physical Functioning in Antiretroviral-Naive HIV-Infected Patients. Open AIDS J. 2018;12(1):117-25.

38. Kunisaki KM, Niewoehner DE, Collins G, Aagaard B, Atako NB, Bakowska E, et al. Pulmonary effects of immediate versus deferred antiretroviral therapy in HIV-positive individuals: a nested substudy within the multicentre, international, randomised, controlled Strategic Timing of Antiretroviral Treatment (START) trial. Lancet Respir Med. 2016;4(12):980-9.

39. Bandera A, Gori A, Clerici M, Sironi M. Phylogenies in ART: HIV reservoirs, HIV latency and drug resistance. Curr Opin Pharmacol [Internet]. 2019;48:24-32. Available from: https://doi.org/10.1016/j.coph.2019.03.003

40. Filteau S, PrayGod G, Woodd SL, Friis H, Heimburger DC, Koethe JR, et al. Nutritional status is the major factor affecting grip strength of African HIV patients before and during antiretroviral treatment. Trop Med Int Heal. 2017;22(10):1302-13.

41. Okulicz JF, Le TD, Agan BK, Camargo JF, Landrum ML, Wright E, et al. Influence of the timing of antiretroviral therapy on the potential for normalization of immune status in human immunodeficiency virus 1-infected individuals. JAMA Intern Med. 2015;175(1):88-99.

42. Sun Y, Fu Y, Zhang Z, Tang T, Liu J, Ding H, et al. The investigation of CD4 + T-cell functions in primary HIV infection with antiretroviral therapy. Med (United States). 2017;96(28):1-9.

43. Russell MK. Functional assessment of nutrition status. Nutr Clin Pract. 2015;30(2):211-8.

44. Leong DP, Teo KK, Rangarajan S, Lopez-Jaramillo P, Avezum A, Orlandini A, et al. Prognostic value of grip strength: Findings from the Prospective Urban Rural Epidemiology (PURE) study. Lancet [Internet]. 2015;386(9990):266-73. Available from: http://dx.doi.org/10.1016/S0140-6736(14)62000-6

45. Santos FB, Conceição-Machado MEP da, Sampaio E de J, Ramos LB, Barreto-Medeiros JM. Reduction of relative handgrip strength and cardiometabolic risk in individuals with HIV/AIDS. Rev Soc Bras Med Trop. 2019;52(0):1-5.

46. Richert L, Mercié P, Bruyand M, Dabis F, Bonnet F, Chêne G, et al. Handgrip strength is only weakly correlated with physical function in well-controlled hiv infection: Anrs co3 aquitaine cohort. J Acquir Immune Defic Syndr. 2014;65(1):25-7.

47. Skupien EC, Lazzari TK, Coutinho SE, Silva DR. The relation between leptin and inflammatory markers with respiratory and peripheral muscle strength in tuberculosis: A case control study. Clin Respir J. 2018;12(11):2559-65.

48. Mhandire K, Mlambo T, Zijenah LS, Duri K, Mateveke K, Tshabalala M, et al. Plasma IP-10 Concentrations Correlate Positively with Viraemia and Inversely with CD4 Counts in Untreated HIV Infection. Open AIDS J. 2017;11(1):24-31. 
49. Caruso P, Albuquerque ALP, Santana P V., Cardenas LZ, Ferreira JG, Prina E, et al. Métodos diagnósticos para avaliação da força muscular inspiratória e expiratória. J Bras Pneumol. 2015;41(2):110-23.

50. Margolis AM, Heverling H, Pham PA, Stolbach A. A Review of the Toxicity of HIV Medications. J Med Toxicol. 2014;10(1):2639.

51. Jannat-Khah DP, Unterbrink M, McNairy M, Pierre S, Fitzgerald DW, Pape J, et al. Treating loss-to-follow-up as a missing data problem: A case study using a longitudinal cohort of HIV-infected patients in Haiti. BMC Public Health. 2018;18(1):1-11.

52. Grangeiro A, Escuder MM, Cassanote AJF, Souza RA, Kalichman AO, Veloso V, et al. The HIV-Brazil Cohort study: Design, methods and participant characteristics. PLoS One. 2014;9(5). 